\title{
ZEN AND THE ART OF ADAPTATION
}

\section{JEREMY STRONG INTERVIEWS PRODUCER AN DY HARRIES}

\author{
Jeremy Strong \\ Writtle College, Chelmsford, Essex \\ United Kingdom, CM1 3RR \\ Jeremy.Strong@writtle.ac.uk
}

\begin{abstract}
This article arises from a 2011 interview with producer Andy Harries. Earlier that year the BBC had aired three ninety-minute adaptations of the detective novels by Michael Dibdin featuring the character Aurelio Zen. The interview and subsequent article focus on the process by which the novels were chosen, the intended audience, casting, international co-financing, changes between page and screen, and the adaptations' relationship to other texts - notably Wallander - also produced by Harries.
\end{abstract}

Keywords: Adaptation, Zen, BBC

This paper seeks to follow one of the less-travelled routes in adaptation studies, examining aspects of production, of industrial and economic determinants, and in particular of producers' attention to audiences. At its core is an interview with Andy Harries, producer of the Zen detective dramas. In January 2011 BBC 1 aired three adaptations of the Aurelio Zen detective novels by Michael Dibdin. These were shown over successive Sunday evenings - at the prime $9 \mathrm{pm}$ slot - and ran for ninety minutes each. The first book in the ten novel series - Ratking - was published back in 1988, and the last - End Games - appeared shortly after Dibdin's death in 2007.

Aurelio Zen, the principal character, is an Italian policeman, originally from Venice but now resident in Rome. His investigations frequently centre on corruption and cover-ups involving the political and business elite, organised crime, the church, and the criminal justice system itself. Through a combination of intelligence, persistence and good fortune Zen - usually - succeeds in negotiating both his cases and his sometimes complex domestic life. Compared to other detective novels they are not remarkable for their plotting - at times plausibility is strained - particularly in some of the later installments. But they are appreciated for their rendering of Italian society. Strong on atmosphere and setting, they often evoke different cities and regions of Italy in detail, and the character of Zen himself, played by Rufus Sewell, is well realized. Not a straightforward hero, and far from infallible, he is sometimes ambivalent about corruption and his duties.

\section{First Responses to the Adaptations}

The adaptations - shot on location in Rome - were slick and stylish, attracting large viewer numbers (5 -6 million) as well as generally positive audience feedback and reviews. "Zen looks great, with snappy 1960s-style zooms 
setting the tone" observed Richard Vine in The Guardian. ${ }^{1}$ The Observer's Andrew Anthony noted that "everything and everyone looked exquisitely beautiful in Zen, a lavish new detective series". ${ }^{2}$ British actor Rufus Sewell had the lead role in a largely British cast. Three different directors were responsible for each of the ninety-minute films. The producer was Andy Harries, who - with his independent company Left Bank Pictures - had also produced (and continues to produce) the adaptations of the Wallander detective novels starring Kenneth Branagh. Like Wallander, the Zen programmes arose from literary originals, enjoyed high production values, and would be broadcast at the favoured 9pm Sunday night slot on BBC1. Similarly, they were co-financed internationally. One of the financing partners was WGBH Boston, an educational public television station run on a non-commercial basis who earmarked Zen for their Masterpiece series, a long- running body of mostly British programmes such as the drama Upstairs, Downstairs, the police thriller Prime Suspect and more recently Downton Abbey. Another financing partner was Mediaset, the largest commercial broadcaster in Italy, controlled by former Italian Prime Minister Silvio Berlusconi, and operating several national and digital terrestrial TV channels. Last, but not least, there was ZDF, the German publicservice broadcaster run, like WGBH, on a not-for-profit basis and who have also screened the British police drama New Tricks.

In terms of their origins, cost of production, and broadcasters these adaptations manifested many of the characteristics of what is frequently called 'quality television'. ${ }^{3}$ Describing the 'modern competitive marketplace within television' Sarah Cardwell (2007) notes how adaptations, frequently presented as 'quality television' - such as Zen and Wallander - are now often the result of collaborations between broadcasters with a Public Service remit. ${ }^{4}$ Although Cardwell's focus is on what she terms 'classic novel' adaptations rather than on contemporary crime/detective works, which she contends are primarily understood by audiences in terms of their genre affiliations rather than as adaptations per $s^{5}$, it is still evident that in terms of the circumstances of their production Zen and Wallander fit the bill for 'quality television'.

\section{Adaptation Studies}

A substantial body of theory and criticism informs the field of adaptation, with George Bluestone's Novels into Film (1957) widely recognised as the first major book-length study ${ }^{6}$ with dozens of monographs and edited collections published subsequently. Three peer-reviewed journals are dedicated to adaptation: Literature/Film Quarterly (since 1973), Adaptation and The Journal of Adaptation in Film and Performance (both since 2008) are solely focused on the subject area, while countless other journals of literature, cinema, television, media and culture routinely contain articles that address instances or issues of adaptation. As one of its principal thinkers, Tom Leitch, observes, "the field is still haunted by the notion that adaptations ought to be faithful to their ostensible source texts". ${ }^{7}$ Notwithstanding that fidelity discourse has been widely criticised in favour of intertextual approaches, there persists a "continued determination of adaptation studies with all the world before it to define its field with primary reference to its closeness to literature". ${ }^{8}$

Furthermore, if fidelity as an evaluative criterion has dogged approaches to adaptation then the tendency to frame the matter principally as a transit of novels to film has proved equally persistent. Cinema remains the assumed norm

\footnotetext{
${ }^{1}$ http://www.guardian.co.uk/tv-and-radio/2011/jan01/zen-bbc-sunday-drama

${ }^{2}$ http://www.quardian.co.uk/tv-and-radio/2011/jan/09/zen-above-suspicion-silent-witness-review

${ }^{3}$ See Sarah Cardwell, 'Literature on the small screen: television adaptations', in Cartmell and Whelehan, eds, The Cambridge Companion to Literature on Screen, Cambridge University Press, 2007, p.192; Mark Jancovich and James Lyons eds., Quality Popular Television; Cult TV, the Industry, and Fans, BFI Publishing, 2003.

${ }^{4}$ In: Janet McCabe and Kim Akass (Eds) Quality TV: Contemporary American Television and Beyond. I.B.Tauris, 2007.

${ }^{5}$ Cardwell in Cartmell and Whelehan, eds, p191.

${ }^{6}$ George Bluestone, Novels Into Film, University of California Press, 1957.

${ }^{7}$ Tom Leitch, 'Adaptation Studies at a Crossroads', in Adaptation, Oxford University Press, Volume 1, issue 1, p 64.

${ }^{8}$ Ibid.
} 
of page-to-screen adaptations with studies that attend to television adaptations and the specificities of that medium - for example Sarah Cardwell's Adaptation Revisited: Television and the Classic Novel (2002) - being comparatively rare. John Caughie points to a relevant example of the interrelationship between television and cinema, identifying the importance of British television in priming "the world audience for the prestige of Britain's literary and theatrical heritage, finding a market for such sumptuous literary adaptations as Brideshead Revisited (1981) and The Jewel in the Crown (1984)"', both produced by Granada Television and aired in the U.S. on Masterpiece. Although Zen, Wallander and other British TV exports do not align to what are described as 'heritage' texts such as Brideshead and Jewel (mostly period-set adaptations of classic novels) their connotations of quality and scheduling by public-service broadcasters reveals an overlapping ancestry.

\section{Zen on Television}

On screen Zen had been realised as a more stylish, sexier, perhaps younger figure than in the books. The entire production was, in fact, notable for its visual appeal. Smart suits, sunshine, a gleaming Alfa Romeo, attractively photographed Roman streets, and a former Miss Italy contestant all coalesced to create a seductive mood, a lighter, 'breezier' feeling than the books.

There were a number of 'structural' changes in Zen's transition from page- to-screen. Firstly, although each of the ninety-minute TV films were based on an individual book, they were not broadcast in an order that corresponded with the publication of the successive novels. Hence, although the criminal investigations broadly matched the equivalent aspects of each of the books, the unfolding of Zen's private life - as it runs from one novel to the next was necessarily obliged to be re-ordered. Secondly, it was apparent that - taken as a whole - the series was weaving a meta-story of conspiracy involving certain recurring characters. This differed from the originals where, though some of Zen's friends and colleagues reappear, there is not an all-encompassing narrative. Thirdly, and relatedly, Zen's screen investigations did not take him to different regions and cities of Italy in the same way as the novels. In the originals, one of the distinctive features differentiating each story is that it transports Zen and the reader from Rome to somewhere different and reflects on the properties of that place, on food, people, topography, architecture. Zen's cases take him to Sardinia, Tuscany, Naples, Milan etc. As a British author resident in Italy, Dibdin was well-placed to reflect - for English-speaking readers - on the regional differences of Italy by presenting them through the prism of a Venetian detective whose work takes him throughout the country, frequently making him feel an outsider.

Reflecting on these changes and differences in emphasis, some questions arose that are common to many adaptations. Why were these texts or this author chosen? What ambitions (or limitations) guided the decision to adapt in this particular way? To what audience are the programmes structured to appeal? Historically, adaptation studies has tended to focus on texts and in particular on case studies, though recently more work has emerged that seeks to unpack and explain adaptations by different means. Claire Monk's Heritage Audiences: Period Films and Contemporary Audiences in the UK (2011) engaged directly with viewers through qualitative empirical analysis, while Simone Murray's The Adaptation Industry: The Cultural Economy of Contemporary Literary Adaptation (2011) examines the complex interplay of institutions dealing in intellectual property as the key - and hitherto under-examined - factor in understanding what gets adapted and how. Mindful of these developments in the field, and without denying in any way the continued usefulness of close and sustained attention to texts, I thought l'd take a break from my established patterns of scrutiny and try asking the producer.

Somewhat to my surprise, Andy Harries immediately agreed to an interview. At least part of my surprise owed to the fact that the future of the Zen TV franchise was at that time in the balance. It had originally been intended that a second run of three programmes would be commissioned. Indeed, although the first three had been aired in the UK, the international co-financing partners envisaged screening all six in a row. Zen has subsequently been decommissioned by the BBC - of which more later - and the series was shown in the US at the end of July 2011. 


\section{Developing a Franchise}

A starting point for the hour-long interview at his London office was Harries' blog for the BBC in which he discussed the opportunities of the ninety-minute format and his wish to develop, following Wallander, a "second upmarket detective franchise for the BBC that would sell potentially around the world". Did a second upmarket detective franchise necessarily entail working from literary properties rather than developing original scripts? The answer was an unequivocal 'yes'. In terms of getting a project funded and off the ground, Harries stated 'It's easier working from books" and "It's about taking a brand to the co-financing partners". So, notwithstanding that Zen was not heavily promoted to audiences as an adaptation - in a way that versions of Austen or Dickens might be - it was certainly key to the project's commencement in terms of the decision-making of international partners: WGBH Boston, Mediaset and ZDF. In a business that remains essentially speculative, having a 'known' from which to work helps secure the go-ahead. This, even though Dibdin had never really sold in Italy (again, it's worth stressing that the novels are not translations - but written in English, by an Englishman) and Dibdin's UK sales had been respectable, but not phenomenal.

The experience of Wallander was clearly critical in determining Harries' approach to the Zen project. He stated that the aim was indeed to 'repeat the formula' in terms of intended audience, time-slot, that the setting be 'foreign' and that a pre- existing detective series provide the stories. His BBC Wallander adaptations had, in his estimation, "built that brand in the UK", which generated increased sales of Henning Mankel's books, as well as helping to create the wider 'Scandi-crime boom'. By way of adding innovation to the formula, as well as seeking to repeat successful elements, he observed that British viewers were "keen on Italy" in terms of "scenery, food, etc." And Harries was wholly candid in stating that Italy was certainly a preferred location for himself, a production team, cast and crew working together for the duration of a shoot. "Well, where would you like to make a programme?", he asked.

\section{Choosing Zen}

Having opted for Italy as a setting, Zen was not the only detective franchise considered. Harries initially contemplated two other literary properties: Andrea Camilleri's Inspector Montalbano series, set in Sicily, and Donna Leon's Commissario Brunetti novels based around Venice.

Both are long-running novel series, starting in the early 1990s and continuing to the present day. The Italian national broadcaster RAI had already adapted Montalbano for the screen and were envisaging more at the time the project was in development, so Camilleri was discounted. Zen was quickly chosen because - in Harries' words - it made a 'companion piece' to Wallander, sharing certain characteristics, but being less psychologically gruelling. The producer wanted "a detective with more style, more wit" and these were certainly elements that would be heightened in adaptation. Dibdin's Aurelio Zen is not infrequently somewhat rumpled, doubting and prone to reflect on the fact of his getting older. By contrast, Rufus Sewell as Zen when asked about sex may remark deadpan "I remember it fondly", however the visual evidence of the adaptation does not cue us to regard our protagonist as a man likely to be mired in a protracted dry spell. The gravitational pull of telegenic beauty dictates to even the meanest understanding that he will shortly, inevitably, be having an affair with his equally lovely new colleague. 


\section{Filming in Italy}

The decision to film entirely in Rome rather than follow the originals to locations around Italy was driven by budgetary limitations. To operate from additional Italian locations would, Harries says, have been "unworkable". As it was, shooting Zen on location in Rome already represented an expensive mode of production, yielding six minutes of cut footage per day, whereas working wholly off sets would deliver twice that. However, the budgetary imperative did align with a key change to the overall narrative trajectory of the three programmes. Harries indicated that the intention had very much been to "develop a longer-running story" to overlay the episode-by-episode narratives and basing every film in Rome and its environs made this far more achievable.

As Cardwell observes, "the best television adaptations continue to use one of television's major strengths: its serial form" ${ }^{10}$ In this instance, it is not a case of television affording the adapter the time and opportunity to set out their stall with a less hurried rendering of a single novel than film form allows. Rather, working over multiple novels, the adaptations invent - or at least significantly expand - the theme of a secret society and conspiracies linking the state and the Catholic church. This is a motif clearly intended to chime with the preoccupations of the massively successful Da Vinci Code novel and film.

There is a loss as well as a gain here. For example, in Dibdin's original novel Vendetta the theme of a disappearance and a closed rural community, where kidnapping has a long tradition, and where an investigator meets a wall of silence, is strongly tied to the author's rendering of Sardinia. Much is made of Zen's failed efforts to pass himself off as a foreign visitor, to not appear as the policeman from Rome. By contrast, the equivalent episode on TV simply relocates these sequences to unspecified countryside outside Rome and the relationship between place and events is necessarily jettisoned.

The three Zen TV-films each had a different director, though the crew remained broadly the same throughout. Screenwriter Simon Burke scripted all three episodes, the third being co-written with Peter Berry. Harries stated that he was "particularly keen" to engage Burke as he was a writer who was resident in Italy, and therefore - Harries felt - well-placed to treat with novels by another Englishman who'd lived in Italy. Burke has done a variety of writing for television, including a substantial amount of adaptation, both of classic fiction (Return of the Native, Persuasion, Sons \& Lovers) and of contemporary literary fiction (White Teeth). But Zen was in no sense presented to audiences as an 'authored' adaptation, or as 'authored' television. By way of comparison, Andrew Davies - screenwriter of the BBC's 1995 Pride and Prejudice and Channel 4's 2005 Bleak House - has, as he says, "first refusal"11 for certain types of British TV adaptation and enjoys considerable prominence as adapter in the publicity and accompanying discourse around his works. Stephen Poliakoff, writer of Shooting The Past (BBC 2, 1999) and The Lost Prince (BBC 1, 2003), occupies an equivalent profile with his original work for TV. Zen, however, was presented as broadly author-less. Neither was Michael Dibdin (now deceased) foregrounded as writer of the novels, beyond the obligatory acknowledgment in the credits. As per Cardwell's observation, these programmes were to be approached by audiences thinking "what type of programme will this be?" and, crucially, "shall I watch it?" essentially in terms of their adequacy to the detective or crime genre, supplemented by such relevant cues as channel and time of broadcast.

Discussing how further episodes of Zen might have been produced, Harries revealed that a switch to hour-long installments was seriously considered. Based on his experience of Wallander, Harries also observed that "we probably would have made greater use of sets too, as it's a more efficient and cost-effective model". Constructing sets, especially for recurring settings that can be used multiple times within episodes and from one episode to the next, is a far less expensive mode than identifying and rigging a substantial number of locations. Necessarily, these two parameters would have required further changes in the adaptation process for any future episodes. Even greater streamlining of original material would have been required to distil novels to the sixty-minute format, and

\footnotetext{
${ }^{10}$ Cardwell in Cartmell and Whelehan, eds, The Cambridge Companion, p.193.

11 'A practical understanding of literature on screen: two conversations with Andrew Davies', in Cartmell and Whelehan, eds, The Cambridge Companion, p.242.
} 
more sequences would require narrative re-location to make use of the 'permanent' sets. If omission or deviation from Dibdin's originals is considered a negative, then these hypothetical Zen episodes would inevitably suffer in the comparison. However, an alternative standpoint might be to observe that those changes would better align them to the particularities of the television medium. Perhaps the ninety minute format is television-trying-to-be-film, while the hour-long TV drama with recurring characters and settings has proved over decades to be a consistently durable and popular format with its own pleasures and potentialities.

Julie Sanders' Adaptation and Appropriation (2006) raises a host of interesting questions about adaptation that apply here, including the key distinction she makes between two different modes of borrowing from originals. Sanders identifies in adaptations the existence of an "inherent sense of play, produced in part by our informed sense of similarity and difference between the texts being invoked". By contrast, appropriation "frequently affects a more decisive journey away from the informing source into a wholly new cultural product and domain". ${ }^{12}$ For the former category, it is as if the defining quality is not constituted in the text itself but in the viewer's foreknowledge of a literary antecedent and a mode of viewing that actively maps memories of the source-text onto the experience of the derived text. Her model of appropriation might apply well to the screen Zen, particularly given that it was not strongly promoted or positioned in terms of its literary antecedents. Hour-long versions, more substantially altered from Dibdin's novels, would certainly fit.

\section{The Audience}

Harries spoke at length about the audience for Zen and about the myriad audience-focused decisions that shaped the production. "The audience, he stated, is everything". Retrospective analysis of the viewership for Zen revealed it to be precisely those for whom it was engineered, "upmarket As and Bs", with an audience of 6.2 million for the first episode and 5.2 million for the last. ${ }^{13}$ These are strong figures, certainly good enough to merit a second series, and were married to an overwhelmingly positive critical reception too. Casting was a central consideration in terms of making Zen for a particular audience. Harries said that Sewell, whilst "perfect" for the part, was not such an easy sell in terms of securing finance because he is primarily known as a film actor. Hence, he was less likely to be familiar to a TV audience, particularly the older viewers who had formed the core of the Wallander audience (and other programmes such as Inspector Morse or Rebus) and who would form the core of the Zen audience. This speaks interestingly to the supposed hierarchy of film and television. Securing a 'film actor' is not an unqualified positive if it jeopardises the elements of familiarity and recognisability presumed to garner a TV audience. I asked specifically whether Harries had considered a Ken Stott 'type' for the role since the books certainly allow for a reading of Zen as older and somewhat worn-down. Whilst he said that, no, he hadn't, he was certainly aware that at least one earlier attempt to film Zen had figured Alfred Molina in the lead, and that in certain respects it would have been easier to get the project financed had he used an older actor more recognisable to a mature British audience.

The decision to cast Italians in the key female roles, most notably Caterina Murano as Zen's colleague and lover, Tania, was driven by Berlusconi's Mediaset. Casting Murano, who like Sewell is primarily known to audiences for film, rather than television work, was instrumental in putting together a package that "would secure Italian co-finance".

Zen has been decommissioned by the BBC. It had got the go-ahead under Jay Hunt but was subsequently axed shortly after Danny Cohen took her role as controller of BBC 1. Prior to this, Cohen had been controller of BBC 3 and had had several roles at Channel 4. His commissions - including $\underline{S k i n s}^{14}$, Supernanny ${ }^{15}$, The World's Strictest

\footnotetext{
12 Julie, Sanders, Adaptation and Appropriation, Routledge, 2006, p 25-26.

${ }^{13}$ Audience figures cited by Harries at interview. See also Broadcasters'Audience Research Board (B.A.R.B.) http://www.barb.co.uk

${ }^{14}$ Teen drama, 2007 - present. UK, featuring controversial storylines that included drug use, mental health and sexual identity.

${ }^{15}$ Reality Television programme, 2004 - present. Originally U.K.-based, but subsequently U.S. A professional nanny assists parents overwhelmed by the challenges of child-rearing.
} 
Parents ${ }^{16}$, The Inbetweeners ${ }^{17}$, and Fonejacker ${ }^{18}$ - testify to a deftly populist judgment about what will succeed and he unquestionably grew the audience share for BBC 3 with programmes aimed at a younger market.

Cohen's stated view was that BBC 1 already offered a sufficiency of "male detectives" and that retaining Zen would have militated against developing a more diverse portfolio of programmes. Harries observed that the problem with Zen was not that he was too male, but "too posh" for Cohen's tastes. Perhaps that specific audience of upmarket As and Bs had been too perfectly and absolutely achieved. Although there has been talk of continuing the series by assembling an alternative funding package, Harries' view is that it is unlikely that the proposed further series of Zen will be made. "Making TV ", he reflected, "is like going to war".

\section{Conclusion}

For this interview, much hinged on Harries' candour. Interviewing the producer at a time when the programmes had already been broadcast and when he regarded future installments as unlikely, may well have been key to the freedom with which he spoke. Certainly, the 'European-ness' of the project was a dimension that became more apparent in interview. Harries' answers often returned to the importance and complexity of assembling a co-funding package and how this necessarily involved including elements that would satisfy multiple participants. Location, cast, and choice of original material were all aspects shaped by Zen's status as a production delivered through a combination of British, U.S., Italian and German finance.

This brief study makes a modest contribution to the growing body of thought that argues for Adaptation Studies to deploy a broader range of approaches, including analyses of audiences, conditions of production and other economic determinants. However, to maintain that the field should not be limited to textual analysis must not, in turn, become a dogma that eschews texts as vital objects of study. Just as auteurist approaches to cinema ran the risk of making movies significant only in terms of what they might tell us about their directors, so it would be a great loss in Adaptation Studies if an 'industrial turn' were, methodologically speaking, to throw the baby out with the bath-water. Consideration of economic, industrial and legal factors in examining how and why adaptations take the shape they do should be a useful part of our critical toolbox, but marginalizing the finished objects (to the extent that texts are ever finished) would be a perverse outcome.

\section{B i o graphy}

Dr Jeremy Strong is Chair of the Association of Adaptation Studies http://www.adaptation.uk.com/ and Head of Higher Education at Writtle College, Essex. He has widely published on adaptation, including articles in Literature/ Film Quarterly, Adaptation and The Journal of Adaptation in Film and Performance. His most recent book Educated Tastes: Food, Drink and Connoisseur Culture was published in 2011.

\footnotetext{
${ }^{16}$ Reality Television programme, 2008 - present. Originally U.K. but subsequently U.S., Australian and German versions. Unruly teens move in with a strict family overseas for a week and endeavour to overcome their problems.

${ }^{17}$ Situation comedy, 2008-2010. UK, with a core cast of teenagers.

${ }^{18}$ Comedy, 2006 - 2010. UK, based on prank calls.
} license does not apply to the media referenced in the article, which is subject to the individual rights owner's terms. 